\title{
O PAPEL DA ESCOLA NO ENFRENTAMENTO DA HOMOFOBIA ${ }^{1}$
}

\author{
Angelita Lúcia de Albuquerque Sousa, Faculdade Santa Maria (FSM), \\ angelita_albuquerque@hotmail.com \\ Cintia Valéria Assis de Queiroga, Faculdade Santa Maria (FSM), \\ cintiaqueiroga@hotmail.com \\ Lúcia Maria Temóteo, Faculdade Santa Maria (FSM), \\ luciatemoteo@gmail.com
}

\begin{abstract}
RESUMO
Este artigo propõe discutir o papel da escola no enfrentamento da homofobia. Para tal, realizou-se um estudo teórico em torno do tema por meio de uma pesquisa bibliográfica, onde foram consultados alguns livros e artigos científicos disponibilizados nas bases de dados Google Acadêmico e Scielo. A homofobia é compreendida como um fenômeno complexo e variado. Podemos enxergá-la em piadas vulgares que ridicularizam as pessoas homossexuais, no entanto, ela pode se revestir também de formas mais brutais, chegando inclusive ao extermínio. Os comportamentos homofóbicos variam desde a violência física da agressão e do assassinato, ainda a simbólica. Tais comportamentos são tão danosos para a vítima que, em muitos casos, leva a sua "expulsão" da escola. O resultado dessa pesquisa mostra com os artigos estudados que para a solução de tal problemática faz-se necessário o apoio de toda a comunidade escolar, bem como o apoio de outras instâncias públicas no que se refere à disponibilização de materiais didáticos necessários para entrada desse debate nesse meio. É importante que os profissionais tenham processos de formação, capacitação e aperfeiçoamento para guiar a sua prática em meio a essas discussões, tendo em vista que discussões nesse sentido ainda hoje são repletas de tabus e preconceitos.
\end{abstract}

PALAVRAS-CHAVE: Educação; Homofobia; Diversidade.

\section{THE ROLE OF SCHOOL IN THE STRUGGLE AGAINST HOMOPHOBIA}

\section{ABSTRACT}

This article aims to discuss the role of the school in confronting homophobia. For that, a theoretical study was carried out around the theme through a bibliographical research, where were consulted some books and scientific articles available in Google Academic and Scielo databases. Homophobia is understood as a complex and varied phenomenon. We can see it in vulgar jokes that mock homosexual people; however, it can also take on more brutal forms, even reaching extermination. Homophobic behaviors range from the physical violence of aggression and murder, still to symbolic. Such behaviors are so damaging to the victim that in many cases it leads to their "expulsion" from the school. The result of this research shows with the articles studied that for the solution of such problem, it is necessary the

\footnotetext{
${ }^{1} \mathrm{O}$ presente trabalho não contou com apoio financeiro de nenhuma natureza para sua realização.
} 
support of the whole school community, as well as the support of other public instances regarding the availability of materials needed to enter this debate in this environment. It is important that education professionals seek training and further training to guide their practice in the midst of these discussions, given that discussions in this regard are still full of taboos and prejudices.

KEYWORDS: Education; Homophobia; Diversity.

\section{EL PAPEL DE LA ESCUELA EN EL COMBATE A LA HOMOFOBIA}

\section{RESUMEN}

Este artículo propone discutir el papel de la escuela en el enfrentamiento de la homofobia. Para ello, se realizó un estudio teórico en torno al tema por medio de una investigación bibliográfica, donde fueron consultados algunos libros y artículos científicos disponibles en las bases de datos Google Académico y Scielo. La homofobia se entiende como un fenómeno complejo y variado. Podemos verla en bromas vulgares que ridiculizan a las personas homosexuales, sin embargo, ella puede revestir también de formas más brutales, llegando incluso al exterminio. Los comportamientos homofóbicos varían desde la violencia física de la agresión y del asesinato, aún la simbólica. Estos comportamientos son tan dañinos para la víctima que, en muchos casos, lleva a su "expulsión" de la escuela. El resultado de esta investigación muestra con los artículos estudiados que para la solución de tal problemática se hace necesario el apoyo de toda la comunidad escolar, así como el apoyo de otras instancias públicas en lo que se refiere a la disponibilidad de materiales didácticos necesarios para la entrada de ese debate En ese medio. Es importante que los profesionales tengan procesos de formación, capacitación y perfeccionamiento para guiar su práctica en medio de esas discusiones, teniendo en vista que discusiones en ese sentido todavía hoy están repletas de tabúes y prejuicios.

PALABRAS CLAVES: Educación; Homofobia; Diversidad.

\section{INTRODUÇÃO}

Este artigo tem o objetivo discutir o papel da escola no enfrentamento da homofobia. Para atingir satisfatoriamente a proposta previamente estabelecida para a elaboração desse artigo, foi realizado um estudo teórico por meio de uma pesquisa bibliográfica acerca da temática delimitada para a presente discussão aqui sugerida. Para isso, recorreu-se a algumas bases de dados, Google Acadêmico e Scielo, assim como livros que forneceram subsídios para fomentar a composição desse artigo. Desse modo, para compor a discussão sobre o tema desse artigo foram escolhidos os textos de diversos autores que discutem a temática da 
diversidade sexual, preconceito, discriminação, violência e homofobia com a interface da educação.

Para começo de conversa, iniciamos essa discussão com o pensamento de (Brandão 2007, p. 07) em relação à educação, na qual ele destaca que:

Ninguém escapa da educação. Em casa, na rua, na igreja ou na escola, de um modo ou de muitos todos nós envolvemos pedaços da vida com ela: para aprender, para ensinar, para aprender-e-ensinar. Para saber, para fazer, para ser ou para conviver, todos os dias misturamos a vida com a educação [...].

Essa posição defendida por Brandão (2007) afirma que a educação ocorre mesmo antes do indivíduo ser inserido no ensino regular ofertado pela educação formal, ou seja, pela escola, assegurando que a educação acontece mesmo antes de um sujeito estar inserido nesse sistema. Assim, a educação pode ser ofertada pela comunidade, pela família, por grupo de amigos, por um grupo social, pela igreja ou por qualquer outro meio em que o sujeito esteja inserido. Por meio dessas instancias sociais esse sujeito aprende costumes, valores, crenças, normas comportamentais, dentre outros componentes da cultura.

Brandão (2007) ainda acrescenta a essa discussão que:

[...] Da família à comunidade, a educação existe difusa em todos os mundos sociais, entre as incontáveis práticas dos mistérios do aprender; primeiro, sem classes de alunos, sem livros e sem professores especialistas; mais adiante com escolas, salas, professores e métodos pedagógicos (Brandão, 2007, p. 10).

É importante destacar e considerar a importância que o meio social possui no processo do educar, visto que, uma determinada realidade pode ser responsável pela assimilação do conhecimento, do surgimento de uma ideia, assim como sobre o modo de desempenhar uma determinada tarefa ou ação. $\mathrm{O}$ espaço das primeiras convivências pode funcionar como o primeiro passo de desenvolvimento da curiosidade ou da criatividade e a partir de então as potencialidades adquiridas pela educação através deste meio podem ser desenvolvidas e aprimoradas pelo ensino ofertado pela escola.

Com base nisso, a escola deve garantir ao seu alunado aprendizagem de conhecimentos, habilidades, competências e valores que são necessários para o processo de socialização do indivíduo. Assim como também deve formar cidadãos críticos, reflexivos, autônomos, conscientes dos seus deveres e direitos e que sejam capazes de compreender a realidade a qual vivem, que estejam ainda preparados para participar da vida social, 
econômica e política do país e assim poder contribuir para a formação de uma sociedade mais igualitária (SALDANHA; NORONHA, 2007).

Saldanha e Noronha (2007) ressaltam ainda que é necessário a cada momento o aluno ser motivado e levado a pensar, analisar, refletir, criar, sintetizar, classificar, estabelecer relações entre os conhecimentos aprendidos, argumentar, avaliar, justificar e ter um posicionamento crítico diante a realidade que o cerca, a fim de possibilitar a problematização de sua realidade em consonância com as demais.

Dessa maneira, compreendendo que o âmbito educacional é composto por uma diversidade de seres que pensam, agem, interagem, se comportam, raciocinam, aprendem, ensinam e se relacionam faz-se necessário o debate a temas relacionados à diversidade, pois como assinala Silveira (2014): “A diversidade está inscrita no cotidiano escolar, nos seus vários sujeitos professores/ as, alunos/as, funcionários/as, pais e mães: brancos/as e negros/ as, meninos e meninas, jovens de ambos os sexos, hetero e homossexuais [...]” (p. 201). Nessa perspectiva, (DINIS, 2008) relata que temas relacionados à diversidade sexual e de gênero tem sido constante na mídia, como novelas, cinemas, revistas, sendo, portanto, de responsabilidade escolar o debate de tal temática.

Debates sobre a diversidade sexual e de gênero foram inclusos a partir do ano de 1970 no meio acadêmico, a partir da forte influência dos grupos feministas, gays e lésbicos, trazendo à tona a exclusão de suas representações de mundo nas instituições escolares. No que diz respeito ao cenário brasileiro, tal temática esteve restrita as áreas como Psicologia, Sociologia e a Crítica Literária, encontrando-se bastante ausente na área educacional. No entanto, a partir dos anos 1990 houve uma reviravolta acerca desta temática, a partir de pesquisas da historiadora Guacira Lopes Louro, em que a mesma retrata a exclusão dos grupos minoritários de gênero na história educacional (DINIS, 2008).

Nessa perspectiva, o âmago escolar deve possibilitar espaços para a discussão, reflexão e problematização dos aspectos relacionados à exclusão de grupos minoritários de gênero tendo como finalidade de amenização e/ou superação dessa realidade que é vivenciada nesse espaço. Além disso, torna-se evidente considerar que a reflexão dessa temática englobe também os aspectos da descriminação sexual, preconceito e violência, os quais compõem a homofobia. 
Dentre as diversas definições utilizadas para conceituar a homofobia Barrillo (2009) a considera como sendo "[...] um fenômeno complexo e variado. Podemos entrevê-la em piadas vulgares que ridicularizam o indivíduo afeminado, no entanto, ela pode se revestir também de formas mais brutais, chegando inclusive ao extermínio [...]” (p. 18). Esse mesmo autor ainda ressalta que a homofobia constitui como sendo a atitude agressiva para com os homossexuais, na qual consisti em classificar o outro ser como anormal ou inferior. E que por meio dessa classificação, esses sujeitos são tidos como "diferentes" dos demais seres por uma questão meramente sexual, contribuindo assim na maioria das vezes a sua exclusão, seja do meio social familiar ou acadêmico.

Junqueira (2012) em seu texto Homofobia: limites e possibilidades de um conceito em meio a disputas, ao problematizar sobre a homofobia elenca que:

[...] o termo costuma ser empregado quase que exclusivamente em referência a conjuntos de emoções negativas (tais como aversão, desprezo, ódio, desconfiança, desconforto ou medo) em relação a pessoas homossexuais ou assim identificadas. Essas emoções, em alguns casos, seriam a tradução do receio (inconsciente e "doentio") de a própria pessoa homofóbica ser homossexual (ou de que os outros pensem que ela seja). Assim, seriam indícios (ou "sintomas") de homofobia o ato de se evitarem homossexuais e situações associáveis ao universo homossexual, bem como a repulsa às relações afetivas e sexuais entre pessoas do mesmo sexo. Essa repulsa, por sua vez, poderia se traduzir em um ódio generalizado (e, de novo, "patológico") às pessoas homossexuais ou vistas como homossexuais (p. 04).

O homossexual é considerado um doente, em que, ele é objeto do olhar clínico e deve submeter-se a terapias as quais a ciência lhe recomenda, em especial os tratamentos com eletrochoques realizados no Ocidente até por volta dos anos de 1960. Se as manifestações mais sutis de homofobia significam uma tolerância em relação a lésbicas e gays, isso só é realizado atribuindo-se a esses indivíduos um lugar silencioso e marginal ou de uma sexualidade considerada secundária, incompleta ou inadequada (BARRILO, 2009).

Essa é a imagem que ainda perdura nos dias atuais sobre o homossexual, o ser doente, subversivo, inadequado, incoerente que necessita ser ajustado ao modelo de heteronormatividade que empregado em nosso meio social. Com isso, percebe-se que a descriminação para com esses indivíduos é intensa e que eles são alvos constantes de retaliação por parte do meio familiar, meio social e até mesmo pelo ambiente escolar. Neto e Agnoleti (2008) ao discutirem Educação para a Diversidade Sexual: a escola enfrentando a 
lesbo-homo-bi-transfobia retratam justamente desse aspecto quando afirmam que "A discriminação contra LGBTT geralmente se inicia no lar, reduto culturalmente ligado ao acolhimento e à ideia de refúgio dos problemas do dia-a-dia [...] (p. 242)" e que "Paralelamente a essa vivência no lar, a Escola muitas vezes reflete e reproduz preconceitos [...] (p.243)".

Levando em consideração esses aspectos apresentados, torna-se evidente o papel que o âmbito escolar dispõe para discutir, refletir e problematizar essa dada realidade que é constantemente vivenciada por diversos indivíduos que frequentam os espaços escolares e o meio social. A partir disso, julgamos relevante que tal temática seja amplamente debatida por educadores, gestores, estudantes e os demais envolvidos com o meio educacional, a fim encontrar meios e mecanismos para o enfretamento desse fato que afeta tantas pessoas.

\section{METODOLOGIA}

$\mathrm{Na}$ tentativa de alcançar o objetivo traçado para essa pesquisa que foi discutir o papel da escola no enfretamento da homofobia, foi realizado um estudo teórico por meio de uma pesquisa bibliográfica, na qual possibilitou as autoras uma maior aproximação com a temática abordada no decorrer do artigo. Segundo (Prodanov \& Freitas, 2013, p.54) a pesquisa bibliográfica é aquela construída:

[...] a partir de material já publicado, constituído principalmente de: livros, revistas, publicações em periódicos e artigos científicos, jornais, boletins, monografias, dissertações, teses, material cartográfico, internet, com o objetivo de colocar o pesquisador em contato direto com todo material já escrito sobre o assunto da pesquisa $[\ldots]$

Por meio dessa modalidade de pesquisa, o pesquisador tem um vasto acesso a diferentes concepções teóricas, posicionamentos e visões sobre uma determinada temática. Dessa maneira, essa modalidade de pesquisa pode permitir uma ampliação do modo como um determinado conteúdo é discutido e compreendido, bem como possibilitar novas formas que um conteúdo venha a ser discutido.

A partir de tal composição de pesquisa, os artigos e livros foram selecionados por meio de aproximação com temática proposta para execução e construção desse artigo. Para essa seleção, os artigos foram consultados através das bases de dados Google Acadêmico e 
Scielo e por meio de leituras previas desse material os respectivos artigos que contemplavam a temática da homofobia e educação foram os selecionados. Para compor a discussão sobre o tema desse artigo foram escolhidos os textos de diversos autores que discutem a temática da diversidade sexual, preconceito, discriminação, violência e homofobia com a interface da educação, são eles: (ALTMANN, 2013), (BORGES et al., 2011), (BORGES; MEYER, 2008), (BORRILLO, 2009); (DINIS, 2008) (JUNQUEIRA, 2012), (NETO; AGNOLETI, 2014), (SILVEIRA, 2014), (TEXEIRA-FILHO; RONDENI; BESSA, 2011).

\section{RESULTADOS E DISCUSSÃO}

Borges et al. (2011) ao realizarem uma pesquisa com vinte professoras de escolas de nível médio e fundamental da rede estadual de ensino, na cidade de Santa Maria, Rio Grande do Sul, sobre a percepção que estas professoras tinham acerca do compromisso e da responsabilidade da escola no enfrentamento de questões como discriminações de gênero e homofobia no âmbito escolar, apontam que:

As escolas pesquisadas não têm um plano específico ou ao menos algo como uma determinação refletida e guiada para lidar com as situações que envolvem gênero e sexualidade, tanto em termos de informações interdisciplinares acerca da temática quanto em termos de ações em casos de discriminações. Assim, as professoras acabam lidando com as situações de acordo com os seus próprios valores, os seus conhecimentos específicos e contextuais e a partir de suas próprias possibilidades que são limitadas tanto pelo formalismo escolar, no sentido de compartimentalizar saberes, quanto pela falta de um norte, ou seja, uma ação que seja informada e que dê respaldo ao professor na sua tarefa de educar de forma humanista e inclusiva $[\ldots]$ (p. 32).

Percebe-se com essa realidade que esses profissionais da educação não tem um respaldo teórico e/ou metodológico para implementar discussões desse gênero na sala de aula, assim como, para guiar sua prática diante de muitas situações preconceituosas e discriminatórias que possam surgir nesse contexto. Fica então a critério do professor estabelecer e/ou abordar ou não essas questões por meio de suas vivências e/ou experiências, limitando-se aquilo que esse profissional conhece sem um maior aprofundamento de um tema está tão presente no cotidiano escolar e no meio social.

Outro aspecto importante trazido por Borges et al. (2011) obtido através de sua pesquisa demostra que: 
[...] muitas discriminações e brincadeiras em torno dos que são ou parecem ser homossexuais são geralmente ignoradas, porque há uma dificuldade no ambiente escolar para definir o que é uma situação homofóbica. O que é homofobia pra uns é apenas brincadeira para outros. Aí reside um dos problemas do conceito; se não houver agressão física extrema que ameace a vida de alguém, o resto parece ser tolerado como uma brincadeira normal dos adolescentes. A questão parece ser sobre esse limite do que é ou não aceitável. As professoras realmente se consideram contra a homofobia, mas é muito comum também entenderem que determinados comportamentos e vestimentas são uma afronta à vida na escola. Como já foi referido antes, é comum a noção de que o bom comportamento dentro da escola deva incluir uma adequação do gênero ao sexo e também à heteronormatividade (p. 33).

Nota-se com esse dado que muita das vezes o conceito homofobia não é conhecido, compreendido e aplicado da forma correta. Gerando desse modo distorções do seu significado, assim como, a negligência ou omissão por parte de quem escuta brincadeiras de cunho desmoralizante para com aqueles que apresentam caraterísticas "diferentes" do modelo de heteronormatividade, bem como a desconsideração de que essa prática não possui gravidade como nos casos de violência física.

Dados semelhantes foram encontrados por Teixeira-Filho, Rondini e Bessa (2011) em relação a:

[...] piadas ofensivas a pessoas homossexuais contadas na escola, encontramos que, embora $42 \quad(43,8 \%)$ não-heterossexuais tenham apresentado uma atitude de enfrentamento da homofobia, o restante escolheu alternativas que indicavam reações típicas de quem se sente constrangid@ (sic), violentad@ (sic), ou então de quem internalizou e aceitou a homofobia, isto é, acha normal rirem das pessoas por conta de sua orientação sexual (p.728).

Sobre esse fato (BORGES; MEYER, 2008, p. 60) consideram que os “[...] comportamentos homofóbicos variam desde a violência física da agressão e do assassinato até a simbólica, em que alguém considera licito afirmar que não gostaria de ter um colega ou um aluno homossexual". Assinalando assim, que qualquer forma de brincadeira desrespeitosa, discriminatória ou preconceituosa que ponha em risco a integridade pessoal e moral de uma pessoa é considerada uma violência na mesma proporção que a rejeição, a agressão física ou até mesmo o assassinato.

Esses comportamentos homofóbicos são tão danosos para a vitima que estes influenciam o sentimento de não pertencimento ao grupo dominantemente heterossexual, fazendo surgir uma sensação de incômodo e intimidação diante dos demais e, em muitos 
casos, leva a evasão escolar (BORGES et al. 2011). Com isso, torna-se evidente que tais comportamentos quando praticados por qualquer parte do corpo da escola, sejam professores, alunos, gestores e funcionários/servidores, podem modificar totalmente a rotina dos seus alunos, principalmente daqueles que são vitimas constantes dessas práticas, podendo assim gerar a desmotivação para a aprendizagem, assim como para a desistência ou evasão escolar como já foi referido acima.

Com base nesses aspectos faz-se necessário buscar mecanismos, estratégias e maneiras para o combate dessa realidade tão evidente e emergente nos espaços escolares. Barrillo (2009) destaca o importante papel que a escola tem na luta contra a intolerância. Ele destaca que:

[...] Ela deve propagar o entendimento de que a igualdade de gays e lésbicas é responsabilidade de todos. Nos cursos e nas apostilas, a homossexualidade e a bissexualidade devem ser apresentadas como manifestações tão legítimas e plenas quanto a heterossexualidade. Além disso, faz-se necessária uma melhor inclusão da ideia de diversidade sexual, bem como da importância dos valores de igualdade e não-discriminação de homossexuais, na formação de profissionais que lidam com determinados aspectos da vida privada dos cidadãos, em particular com sua sexualidade [...] (p.44) .

Neto e Agnoleti (2004) ressaltam ainda a importância da parceria entre a família e a escola para o enfretamento e superação dessa realidade. Dessa forma, a relação escola-família deve, no lugar de constituir uma parceria de exacerbação da opressão, possibilitar a tolerância, a compreensão, a valorização da diversidade e o respeito, tendo em vista que somos seres que temos valores culturais, crenças e maneiras de pensar que são nos passados em primeira instância pelo meio familiar, torna-se importante que a escola e a família sejam aliadas na transformação de tantos ambientes escolares opressores, preconceituosos, discriminatórios e em muitas vezes de grande violência.

Outra faceta importante de ser destacada é que o estudo referente ao tema da sexualidade e diversidade sexual no contexto da escolar precisa encontrar amparo institucional para se inserir nas salas de aulas de todos os professores (as), necessitando receber apoio não apenas da secretária de educação, mas do governo do estado, de organizações não governamentais e de órgãos públicos (BORGES; MEYER, 2008). Vemos dessa forma, que a integração entre essas diversas esferas públicas podem também auxiliar no debate e consequentemente no processo de enfrentamento dessa dada realidade. A temática 
da diversidade deve esta ainda inclusa no currículo de formação de professores, para que os novos profissionais da educação possam desenvolver e fortalecer futuramente estratégias de resistência do currículo heteronormativo como aponta (ALTMANN, 2013).

Tratar de temas pertinentes à diversidade sexual em sala de aula na atualidade ainda é um desafio para muitos professores, especialmente pelas reações de violência e descriminação praticamente indomável por parte dos alunos. Além disso, a falta de recursos didáticos para abordar esse tema de forma transversal, assim como a própria falta de preparo profissional e a ausência desse tema na formação de professores são fatores favorecem para uma repetição de atitudes e conteúdos discriminatórios em sala de aula, além também de serem algumas das principais queixas trazidas por professores em uma pesquisa realiza por (BORGES; MEYER, 2008).

Para o combate dessas práticas discriminatórias faz-se necessário discutir tal temática a partir de novas políticas de inclusão das minorias sexuais e de gênero por parte dos educadores, através de uma nova linguagem que se mostre resistente a padrões homofóbicos. Outras possíveis estratégias no combate a homofobia seriam incluir na grade curricular da formação em educação estudos sobre gêneros e diversidade sexual, por meios de divulgação de novas pesquisas bibliográficas. Entretanto, ações micropolíticas também podem ser desenvolvidas, que podem ser realizadas pelos educadores através de análises críticas com os

discentes sobre homossexualidade e heterossexualidade. Dessa forma, percebe-se a importância do fazer pedagógico reinventar-se continuamente, a fim de liberar a vida onde ela encontra-se aprisionada (DINIS, 2008).

\section{CONSIDERAÇÕES FINAIS}

Diante de todos os aspectos apresentados ao longo desse artigo, torna-se evidente que a escola tem um papel imprescindível no enfrentamento de questões ligadas a discriminação, rotulação e qualquer forma de preconceito para com a diversidade sexual. O meio escolar deve propiciar e fomentar espaços para o diálogo, a discussão, reflexão e desmistificação dos muitos preconceitos que circundam a temática da diversidade sexual e consequentemente a homofobia. Entretanto, o que se vê que também é um lugar de exclusão, é um lugar de 
descriminação, é um lugar de expulsão de pessoas que estão fora dessa heteronormatividade, é um lugar de violência.

Apesar de todas as dificuldades encontradas por professores para tratar dessa temática no meio escolar, é necessário haver a superação dessas dificuldades. Para isso, é indispensável o apoio de toda a comunidade escolar, como os gestores, funcionários e a família, assim como o apoio de outras instâncias públicas no que se refere à disponibilização de materiais didáticos pedagógicos necessários para entrada desse debate nesse meio. É preciso ainda, que esses profissionais tenham processos de formação, capacitação e aperfeiçoamento para guiar a sua prática em meio a essas discussões, tendo em vista que discussões nesse sentido ainda hoje são repletas de tabus e preconceitos. O conhecimento aprofundado sobre o tema pode, desse modo, servir para a desmistificação e quebra de muitos preconceitos ainda existentes nesse espaço.

É necessário destacar ainda que, as questões relacionadas à homofobia não se faça apenas por parte de textos legais e bem redigidos, mas que seja internaliza por parte de todos os profissionais da educação. Para que então essa realidade seja modificada e o ambiente escolar seja um espaço para a aprendizagem e para o acolhimento da diversidade e pluralidade de seres.

\section{REFERÊNCIAS BIBLIOGRÁFICAS}

ALTMANN, H. Diversidade sexual e educação: desafios para a formação docente. Rio de Janeiro: Sexualidad, Salud y Sociedad-Revista Latinoamericana, n. 13, p.69-82, abril 2013. Disponível em:< http://www.redalyc.org/pdf/2933/293325757003.pdf >. Acesso em 28 de julho de 2017.

BORGES, Z. N. et al. Percepção de professoras de ensino médio e fundamental sobre a homofobia na escola em Santa Maria (Rio Grande do Sul/Brasil). Curitiba: Educar em Revista, n. 39, p. 21-38, jan./abr. 2011. Disponível em: <http://www.scielo.br/pdf/er/n3 9/n39a03. pdf>. Acesso em: 22 de julho de 2017.

BORGES, Z. N.; MEYER, D. E. Limites e possibilidades de uma ação educativa na redução da vulnerabilidade à violência e à homofobia. Rio de Janeiro: Ensaio: avaliação e políticas públicas em educação, v. 16, n. 58, p.59-76, jan./mar. 2008. Disponível em:

〈http://www.scielo.br/pdf/ensaio/v16n58/a05v1658.pdf >. Acesso em: 22 de julho de 2017.

BORRILLO, D. A homofobia. In: LIONÇO, T.; DINIZ, D. (orgs.). Homofobia \& Educação: um desafio ao silêncio. Brasília: LetrasLivres, 2009, p. 15-46. Disponível em 
<http://www.sxpolitics.org/ptbr/wpcontent/uploads/2009/05/homofobiaeeducacao. pdf $>$. Acesso em: 28 de julho de 2017.

BRANDÃO, C. R. O que é educação. São Paulo: Brasiliense, 2007.

DINIS, N. F. Educação, relações de gênero e diversidade sexual. Educação \& Sociedade [online], Campinas, v. 29, n. 103, maio/ago. 2008. Disponível em: < http://www.scielo.br/pdf les/v2 9n103/09.pdf>. Acesso em: 02 de agosto de 2017.

JUNQUEIRA, R. D. Homofobia: limites e possibilidades de um conceito em meio a disputas. Rio Grande do Norte, Bagoas-Estudos gays: gêneros e sexualidades, v. 1, n. 01, p. 01-22, jul./dez. 2012. Disponível em: < https://periodicos.ufrn.br/bago as/article/viewFile/225 6/1689>. Acesso em 08 de agosto de 2017.

NETO, J. B. M.; AGNOLETI, M. B. Educação para a Diversidade Sexual: a escola enfrentando a lesbo-homo-bi-transfobia. In: FLORES, E. C.; FERREIRA L. DE F. G.; MELO, V. L. B. (orgs.). Educação em Direitos Humanos \& Educação para os Direitos Humanos. João Pessoa: Editora Universitária da UFPB, 2014, p. 231-259.

PRODANOV, C. C.; FREITAS, E. C. Metodologia do trabalho científico: métodos e técnicas da pesquisa e do trabalho acadêmico. 2.ed. Novo Hamburgo: Feevale, 2013.

SALDANHA, L. M. L.; NORONHA, E. M. Escola publica democrática: funções e compromissos. São Luís: Ministério Público do Maranhão. 2007.

SILVEIRA, R. M. G. Ambiente escolar e direitos humanos. In: FLORES, E. C.; FERREIRA L. DE F. G.; MELO, V. L. B. (orgs.). Educação em Direitos Humanos \& Educação para os Direitos Humanos. João Pessoa-PB: Editora Universitária da UFPB, 2014, p. 201 -230.

TEIXEIRA-FILHO, F. S.; RONDINI, C. A.; BESSA, J. C. Reflexões sobre homofobia e educação em escolas do interior paulista. São Paulo: Educação e Pesquisa, v. 37, n. 4, p. $725-$ 742, dez. 2011. Disponível em: 〈http://www.scielo.br/pdf/ep/v37n4/a04v37n4. pdf >. Acesso em 22 de julho de 2017. 